\title{
Tim Steckel: the physicians and nurses are the hospital's engine and I am the oil that keeps the engine working properly
}

Received: 02 May 2018; Accepted: 22 May 2018; Published: 24 May 2018. doi: 10.21037/jhmhp.2018.05.01

View this article at: http://dx.doi.org/10.21037/jhmhp.2018.05.01

\section{Expert's introduction}

Born on June 14, 1982, in Henstedt-Ulzburg near Hamburg, Germany, Tim Steckel (Figure 1) went to school in Hamburg until 2001 ending with a 13-school-year career and German high school diploma called Abitur. His eleventh school year Mr. Steckel spent in Portage, Indiana, getting to know American culture as a foreign exchange student. After school Mr. Steckel did his community service in lieu of military service for almost one year and then started his dual study programme to become an industrial engineer which means he went to college and had a practical training at the University Medical Center Hamburg-Eppendorf. After college he continued working at the University Medical Center Hamburg-Eppendorf and left for a new Job at the Klinikum Ernst von Bergmann in 2008. There Mr. Steckel was responsible for the outpatient centers, the controlling department, the IT department, the finance and accounting department and now is the Director Business Management and authorized officer of the hospital.

In light of Mr Steckel's rich experience in hospital management, $7 H M H P$ is honored to invite Mr. Steckel for an interview as a highlight for the featured column "Meet the Experts: the Cutting Edge in Hospital Management".

\section{Be the oil that keeps the engine (physicians and nurses) working properly}

FHMHP: Could you share with us when and how did you start your career as joining the management team of a bospital?

Mr. Steckel: I started working in hospital management already during my college time. I was a dual study programme student which means I went to college and had a practical training at a company. My company was

the University Medical Center Hamburg-Eppendorf so I started working in the health care sector in 2002. It was actually a coincidence that I ended up in the healthcare sector because I had the desire to become an industrial engineer and the University Medical Center HamburgEppendorf thought I was a good fit and picked me. Now, I am very glad things worked out this way.

FHMHP: How long have you been working in Klinikum Ernst von Bergmann gemeinnützige GmbH?

Mr. Steckel: I came to Potsdam at the beginning of 2008. I started working as the chief operating officer of the outpatient center of the Klinikum. After that I got the honor to start a new centralized controlling department, then followed the IT-department and finally the finance and accounting department. Since January of 2017 I am the Director Business Management in Klinikum Ernst von Bergmann gemeinnützige GmbH.

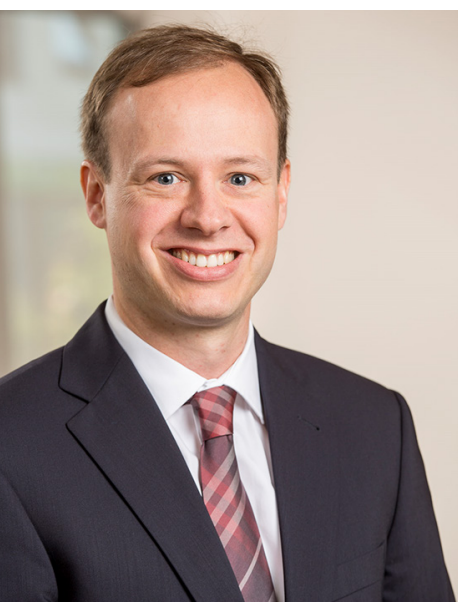

Figure 1 Mr. Tim Steckel. 
JHMHP: What is your daily routine as the Director Business Management in Klinikum Ernst von Bergmann gemeinnützige GmbH?

Mr. Steckel: My job is to keep our hospital running as smoothly as possible. I tend to say the physicians and nurses are the engine and I am the oil that keeps the engine working properly. My daily routine includes business meetings with our leading physicians as well as employees in the administration. I also work closely together with the head of nursing in developing new strategies of recruiting and education.

\section{FHMHP: Could you share us any experience contributing} to your success in your managing role of the hospital?

Mr. Steckel: I always try to meet all my employees at eyelevel so they do not feel aggrieved. I always try to be polite, trustworthy and reliable. These characteristics are essential in my daily success as the Director Business Management in our Klinikum.

\section{Know your staff and their necessities in hospital management}

FHMHP: What do you think are the key elements in hospital management?

Mr. Steckel: Always to know where one stands. This is important with regard to your market knowledge (competitors, insurances as payers, legislation, etc.) your financial assets as well as your human resources. Delivering health care is a service that is rather personnel-intensive. Therefore, knowing your staff and their necessities is very important.

FHMHP: Germany is prestigious in terms of medical level, attracting many international fellows coming for training each year. What do you think is the advantages of the bospitals in Germany?

Mr. Steckel: The German health care system is solidary with regard to how the insurance system works. It is fairly well budgeted so the level of possibilities of medical care is high. The medical education is also good therefore also international fellows like to seek for an opportunity of experiencing German health care. The industry of medical technology as well as pharmaceuticals also plays its role in supporting the German health care market. There is still a broad number of companies with its worldwide or European headquarters in Germany and with regard to their research and development they like to involve German university medicine.

Take Klinikum Ernst von Bergmann gemeinnützige $\mathrm{GmbH}$ as an exmaple, it is set up in the city center of Potsdam, a city with almost 200,000 inhabitants. It is in the greater Berlin area and offers a broad spectrum of medical services. We are set in a very attractive and growing region and will therefore look to grow and consequently enhance our medical portfolio and services.

FHMHP: How is the hospital system runs in Berlin and Germany on the whole? E.g., how can a patient in Germany seek medical help?

Mr. Steckel: There are different ways for a patient to seek medical help and in this special case the help of a hospital. If the case is an elective case the patient will be sent by his GP or a specialist that works in the ambulatory sector. The patient will receive an appointment and then come to the hospital for the necessary services. If the case is an emergency case the patient will come by helicopter, ambulance or on his own to the emergency department where the decision will be made whether the patient needs inpatient care or not.

JHMHP: How are the hospital level and quality graded in Germany?

Mr. Steckel: Unfortunately there is not one release that grades hospital services but many different ones. For example almost each one of the large insurance companies has its own ranking. Then there are patient portals that rate hospitals. And there are different magazines like the "Fokus" that rate the specialists of the different hospitals.

FHMHP: From your perspective, how would/should the hospital embrace the new development in medical field in terms of advanced technology and trends of treatment modality? E.g. artificial intelligence, healthcare provided over Internet, MDT etc.

Mr. Steckel: Our hospital is fully digitized. In the near future we are looking to share this data with others to enhance the care of each patient, of course with the written 
consent of each patient. We are also looking in possibilities of increasing automation as the availability of necessary qualified employees is decreasing.

FHMHP: How is the quality management realized in Klinikum Ernst von Bergmann gemeinnützige GmbH?

Mr. Steckel: We have a special department that works on quality management. We are certified by DIN ISO 9001. Our goal is a continuous enhancement of our quality by constantly relying on the pdca-cycle (plan, do check, act).

\section{HMHP: The business side of the healthcare is vital to} the lifeline of the system, especially in hospitals. In your opinion, how to ensure patient care and in the success of the hospital as a whole?

Mr. Steckel: The hospital system in Germany is funded by two sides. Investments should be financed by the state while operating costs are supposed to be covered by the insurances. This idea is not necessarily bad. However, if one side doesn't provide enough the system gets unbalanced. That is a problem that needs to be solved. Another problem of the German market is the number of hospitals. If there were fewer hospitals, the money for investments would be better allocated and the qualified employees would be better spread. The entire system would benefit if the number of hospitals was reduced.

\section{JHMHP: Over the years, what challenges have you encountered in your role?}

Mr. Steckel: As mentioned above the continuous struggle to stay economically healthy while still being an attractive company for new staff is the main challenge we have to be successful in.

\section{FHMHP: Could you please share with us one most unforgettable story during your career?}

Mr. Steckel: One of my biggest tasks was to implement an electronic medical record (EMR) into the existing software in our hospital. To do so I formed an interdisciplinary project team including physicians, nurses and IT-experts. Together we worked for about 9 months on developing and implementing the EMR as well as train our staff on working with it. Today it is a huge benefit to be fully digitized and I don't think anybody would want to go back to working paper based.
FHMHP: Looking back, could you share with us your philosophy of hospital management in practice?

Mr. Steckel: Being polite, trustworthy and reliable while also having the necessary expertise in hospital management and the health care system in general are the goals I am striving for each and every day.

\section{FHMHP: As a successful director, what would be your} advice to younger generations in pursuing their dreams in the bealthcare sector?

Mr. Steckel: Never stop believing. When people tell you that what you are looking for isn't possible, try to prove them wrong and show them that there are no limits. Health care is a very exhausting business and in Germany there are other industries that are economically probably more interesting for an individual. However, what we do, while working in this industry is generating health-what could be more rewarding.

\section{Acknowledgments}

Funding: None.

\section{Footnote}

Provenance and Peer Review: This article was commissioned by the editorial office for the series "Meet the Experts: the Cutting Edge in Hospital Management" published in Fournal of Hospital Management and Health Policy. The article did not undergo external peer review.

Conflicts of Interest: The author has completed the ICMJE uniform disclosure form (available at http://dx.doi. org/10.21037/jhmhp.2018.05.01). The series "Meet the Experts: the Cutting Edge in Hospital Management" was commissioned by the editorial office without any funding or sponsorship. Grace S. Li reports that she is a full-time employee of AME publishing company (publisher of the journal). The author has no other conflicts of interest to declare.

Ethical Statement: The author is accountable for all aspects of the work in ensuring that questions related to the accuracy or integrity of any part of the work are appropriately investigated and resolved. 
Open Access Statement: This is an Open Access article distributed in accordance with the Creative Commons Attribution-NonCommercial-NoDerivs 4.0 International License (CC BY-NC-ND 4.0), which permits the noncommercial replication and distribution of the article with the strict proviso that no changes or edits are made

doi: 10.21037/jhmhp.2018.05.01

Cite this article as: Li GS. Tim Steckel: the physicians and nurses are the hospital's engine and I am the oil that keeps the engine working properly. J Hosp Manag Health Policy 2018;2:24. and the original work is properly cited (including links to both the formal publication through the relevant DOI and the license). See: https://creativecommons.org/ licenses/by-nc-nd/4.0/.

(Interviewer: Grace S. Li, JHMHP, jhmhp@amegroups.com) 